\title{
Sustainable intraurban cities: the Moema Tinoco Project in the city of Natal, Brazil
}

\author{
D. Cunha Lima Neto ${ }^{1}$, P. Italo dos Santos Galvão ${ }^{2} \&$ K. Brandão ${ }^{3}$ \\ ${ }^{1}$ Legal and Urban Planning Department of \\ Professor Diogenes da Cunha Lima, Brasil \\ ${ }^{2}$ Federal University of Rio Grande do Norte, Brasil \\ ${ }^{3}$ Dcasa Urbanism, Brasil
}

\begin{abstract}
The present work consists of demonstrating, through a project located in an area of 121.67 hectares, Environmental Protection Zone-9 in Natal, Brazil, the building of sustainable social housing. In addition to this, the project also involves improvements in infrastructure, through the implementation of urban equipment and community, aimed at social, economic and environmental urbanization. The architectural project shows us the possibility of building social housing seeking an integration with the surrounding population, respecting sustainable ideas. The project was explained in Public Hearing for the purpose of the regulations of the Environmental Protection Zone-9 in Natal, Brazil, still pending. Furthermore, there was a meeting with the regional manager of Civil Construction of the Caixa Economica Federal (CEF) in RN, Ivonaldo Henrique de Souza, at which he showed considerable interest in the proposal. Marcelo Rosado, Municipal Secretary of Environment and Urbanism, in turn, considered that it is necessary to raise awareness of the importance of sustainability. As a partial result had also a meeting with Homer Grec, Housing Secretary, Project and Land Regularization Structuring, when he made alarming data about the housing deficit in Natal and claimed that in the north there is no urban voids with sufficient capacity for social housing in the range 1, although there are CEF resources for this purpose through the Casa Azul Seal CEF.

Keywords: sustainable, social housing, urban strategies, quality of life, urban poor, development, technology, environment, project, intraurban.
\end{abstract}




\section{Introduction}

The social housing is associated directly to the need to provide urban housing for the disadvantaged sectors of the population. Such housing can be provided by the public or private sector, for sale or rent to its residents.

In this sense, this paper aims to demonstrate how a sustainable social housing project in Natal, Brazil, can contribute and benefit low-income populations.

One of the issues surrounding the project are local practices, since it is intended to introduce new values to management, such as participation, planning, strategy, followed by the appreciation of local traditions, which help to strengthen regional identity and such facts is not common in Brazil, mainly in the northeast.

So the paper in the first part tries to bring a general notion of planning and sustainable neighborhoods in order to give birth to the Moema Tinoco Project wants to apply in Natal. In the second part, we will contextualize and discuss the North Zone of Natal, where the project will be executed. Finally, the third part will be treated on the Sustainable Social Housing mentioning its benefits and challenges for the region.

\section{Auto sustainable and planning neighborhood}

The concept of planned neighborhood came up with the growing demand for more orderly cities, aiming to provide a better infrastructure to residents, joining the efficiency factors, quality of life and sustainability.

This type of sprawling cities results in big displacements, often encouraging use of cars. This model is a contradiction efficiency, low cost, quality and negative impacts on the environment. On the other hand, the efficient city is compact city that combines a diversified occupation in use, covering horizontal housing, vertical, commerce, service, offices, common spaces for leisure and integration with green areas. In addition to this diversity of use, diversity of residents is also essential for the neighborhood to be auto sustainable in the economic and social aspects.

In order to consider this diversity of use and occupation, the planned neighborhoods, in general, are based on large areas (over $500000 \mathrm{~m}^{2}$ ) integrated the consolidated urban fabric and offer a wide variety of products: horizontal and vertical residential, trade, industry, services and leisure, surrounded by parks and green areas. Their projects must provide a proper road hierarchy, which includes the car, public transport, bicycle paths and pedestrian routes.

The urban concept of planned neighborhood has been widely reported by the New Urbanism, a movement that emerged in the United States during the 1990s as a counterpoint to American cities developed so far in more sprawling models where the car is privileged instead of pedestrian.

Speaking of new urbanism, by itself, would give another article, but it is important to highlight some important aspects that coincide with the proposal of a planned neighborhood self-sustainable and in harmony with the environment and quality of life. 
Diversity of use, diversity of classes, democratization of public spaces, construction planning allowing its integration with pedestrian scale, encouraging the use of bicycles and privilege to pedestrians in urban design that includes the lease of community facilities such as schools, parks, health centers and security in order to integrate the community, are some aspects of new urbanism aimed, in short, offer better quality of life for the final and current population of planned neighborhoods.

One of the key factors for success of planned neighborhoods, of course, is the establishment of rules and management of their occupation. Despite the relevance of the urban concept with regard to urban design, the use of each building will define the dynamics and the organization of life of this community.

Since the concept of "Planned" defines the neighborhood, ensure the main aspects that underlie this concept, and, live, work, study and have fun in a harmonized and integrated space to the environment, it is essential to achieve the success in this deployment.

Thus, some planned neighborhoods deployed in Brazil are prime examples of this management, as care of this was one of the pillars of its support. Pedra Branca in the city of Palhoça; Riviera de São Lourenço, in the city of Bertioga and Jurerê International in the city of Santa Catarina, are examples that careful management in the occupation results in the success of its implementation. Highlighting, however, that in all these cases the entrepreneur's management was present since the initial deployment time to the consolidation of these neighborhoods, that is, for more than a decade.

This is a point of consideration, as are models that require a significant management structure and constant, and often mismatched with the profitability of the business, despite its great benefits.

Another model with examples in Brazil are planned neighborhoods of Cia City, deployed in the 1940s, which sought this order through the implementation of restrictions on the use of the Real Estate Registration, dismissing the management structures and the presence of the entrepreneur after deployment urban infrastructure.

Are distinct and positive and negative aspects models in each of them, but both emphasize the importance of this matter to the success of planned neighborhoods, namely the establishment of rules of occupation and community management.

The economic and financial structuring of planned neighborhoods can be considered as one of the main challenges in its implementation. Aspects such as the occupancy rate, growth velocity of Brazilian cities, Brazilian legislation, the profile of the housing construction industry, among others, significantly impact the quality of economic and financial developments.

The occupation rate is an important factor for economic and financial equilibrium of projects planned neighborhoods. On the one hand, the structure necessary to deploy a planned neighborhood in general is robust and high demand degree of investment in time, human and financial resources on the other hand, these usually take years to start the process of consolidation.

Generally, consolidation and acceleration of the implementation process of these projects takes between ten and 20 years to win a consolidated neighborhood 
setting, trade and services supported by own demand and the consecration of a new vector of development.

Thus, the enterprising must be prepared for a long-term planning, but mainly overcome the challenges of having a balanced economic and financial project for each stage of development to be sustainable under these aspects. This is the big challenge, how to make ensure a balance of profitability since the start of this operation, which requires high levels of investment, mainly in urban infrastructure, with prices that are still in the early levels and high risk?

This aspect gets worse when these entrepreneurs are bound to a capital structure with short and medium-term visions, as is the case of companies with publicly traded and they need to demonstrate their returns each year. So make every launch stage presents its results in the levels of each company becomes even more challenging, since the beginning of the implementation of these neighborhoods will require high investments with initial selling prices, as explained above.

Another aspect that directly affects the occupancy speeds linked to rates of population and economic growth of cities. For a new neighborhood project can be consolidated, it must be associated with a city's growth capacity to which it belongs. Projects such as these can easily reach 40 thousand inhabitants, it is necessary that the city has this offer absorptive capacity so there is a good relationship between supply $\mathrm{x}$ demand in order to maintain an adequate level of continuous appreciation of each product offered, as well as its implementation within a reasonable time.

It is true that we are experiencing a very promising period in our country with significant volumes of public and private investments that are generating high growth expectations in several Brazilian cities and projections of sustained economic growth in the coming years. This is a great opportunity for these new projects.

Brazilian law directly affects the development of planned neighborhoods. Some aspects, such as the maximum execution time of infrastructure, constant in the law 6.766/1979 parceling of urban land, of two years, renewable for another two years, since the municipality permits, imposes on the enterprising the challenge of properly scale the size each stage of the project for the execution of the infrastructure to track your sales velocity. An error at this design, sometimes by unpredictable factors, may cause a major financial imbalance in the venture.

Another important aspect related to the Brazilian legislation that can impact the project's occupancy velocity is the fact that there are two processes for creating these projects. The first parceling is tied to the soil, which aims to generate urbanized lot, and the second to the real estate development aimed at generating unit built for marketing, whether for housing, commerce, service or business.

In some cases, the second stage can only occur after the first, with the necessity of run all the infrastructure and obtaining Construction Verification Agreement (TVO). In this case, the start of the distribution process of the units through real estate development will occur after all the investment infrastructure, causing a large mismatch of investment revenue. 
The profile industry of the Brazilian real estate construction still has some features that make the consolidation of planned neighborhoods to occur in the medium and long term.

Regarding verticalized products, long production cycles associated with these products make the occupation began is after the beginning of the marketing year and can easily reach four years, considering that after the delivery of the units there is still the internal adjustment period these units, since it is not common in our industry the units are delivered completely furnished for quick occupation.

In speaking of horizontal units, the Brazilian culture of autoconstruction is still very strong, especially in medium and high standard products. Thus, when finalizing a subdivision, generally after two years of its launch, it begins the process of construction of the units; it is not uncommon that these subdivisions take around three years to achieve an occupancy of $50 \%$.

Surely, if our industry was consolidated in industrial processes and low production cycles, whether for upright products as well as for horizontal units in the segments of medium and high standard, we would watch occupation processes and training of planned neighborhoods at a higher pace.

Obviously, the transformation industry is something that has been occurring and should be accelerated with a shortage of manpower requiring on the one hand, construction with shorter production cycles by dry processing and construction and, on the other hand, will inhibit the autoconstruction that will not be attractive in its cost $\mathrm{x}$ benefit ratio, as already occurred in other markets such as the US and Mexico.

At the same time as a planned neighborhood project earns major risks proportional to its complexity undoubtedly they are also great opportunities. In this sense, the next chapter we will contextualize the northern zone of Natal and then approach the Moema Tinoco Project through the federal government Sustainable Program "My House, My Life" working the idea of a planned neighborhood.

\section{Environmental Protection Zone-9 in Natal, Brazil: context and reality}

In the state of Rio Grande do Norte, $43 \%$ of the population is located in the Greater Natal [1]. This high concentration of population and their growth contributes in the production of alarming situations, such as the occupation of improper areas (Permanent Preservation Area, swamps, river banks, dunes etc.) which is aggravated by the absence of a basic sanitation system, covering the collection, treatment and proper disposal to the sanitary sewer.

The Environmental Protection Zone-9 is located between the municipal boundaries of Natal/RN and Extremoz/RN, eastern coastal state of Rio Grande do Norte, in northeastern Brazil, as shown in Figure 1.

It also includes part of the Lagoa Azul and Pajussara neighborhoods, located in the north of the city of Natal/RN. Important to clarify that the neighborhood of Redinha presents a small part located within the ZPA-9 limits. Today, however, the limits of this neighborhood are still being discussed between the managers of 


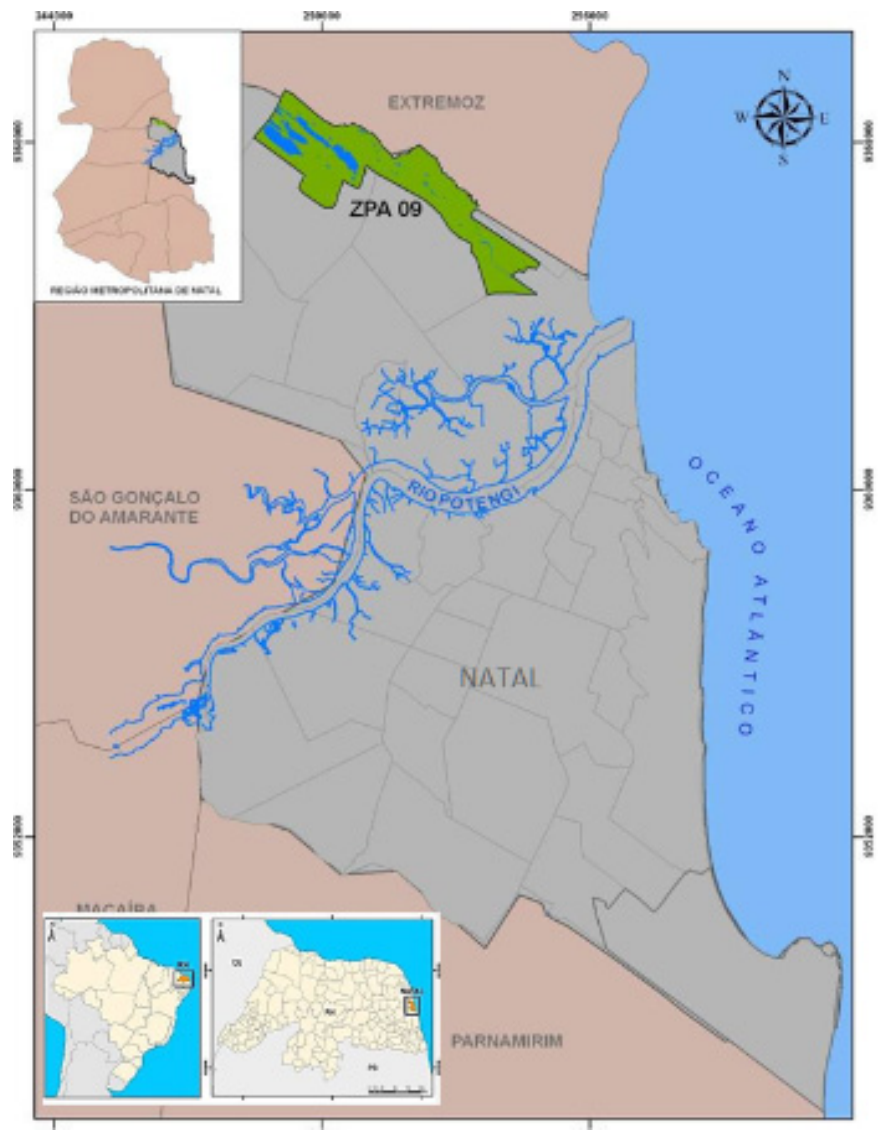

Figure 1: $\quad$ Localization of ZPA-9.

the cities of Natal/RN and Extremoz/RN. For this reason, coupled with the small population density checked, we will not consider it as belonging to the study area.

The article 19th of the Director Plan of Natal, in turn, points to the regulation of each of Environmental Protection Zone and guides for them to be regulated by observing the characteristics of their physical environment and according to three levels of zoning, as defined: subzone preservation, subzone conservation and restricted use sub-area. Such legislation constitutes an important instrument in urban and environmental management, in that it sets out the conditions (limits and potential) use and occupation of these spaces, which, once established, must be strictly observed.

In this reasoning, a technical study (Expert Report) has been prepared in order to meet a request of the 45th Prosecutor's Office of Natal District of Environmental Defense to the Federal University of Rio Grande do Norte, through the Northern Rio-grandense Foundation Research and Culture-FUNPEC [2], and was aimed at evaluating the proposed regulations ZPA-9, prepared by the Brazilian Institute of Municipal Administration - IBAM in partnership with the 
Municipal Secretary of Environment and Urbanism - SEMURB, proponent agency [3], as photo below that shows the area of Environmental-9 Protection Zone can be part of the occupation and land use:

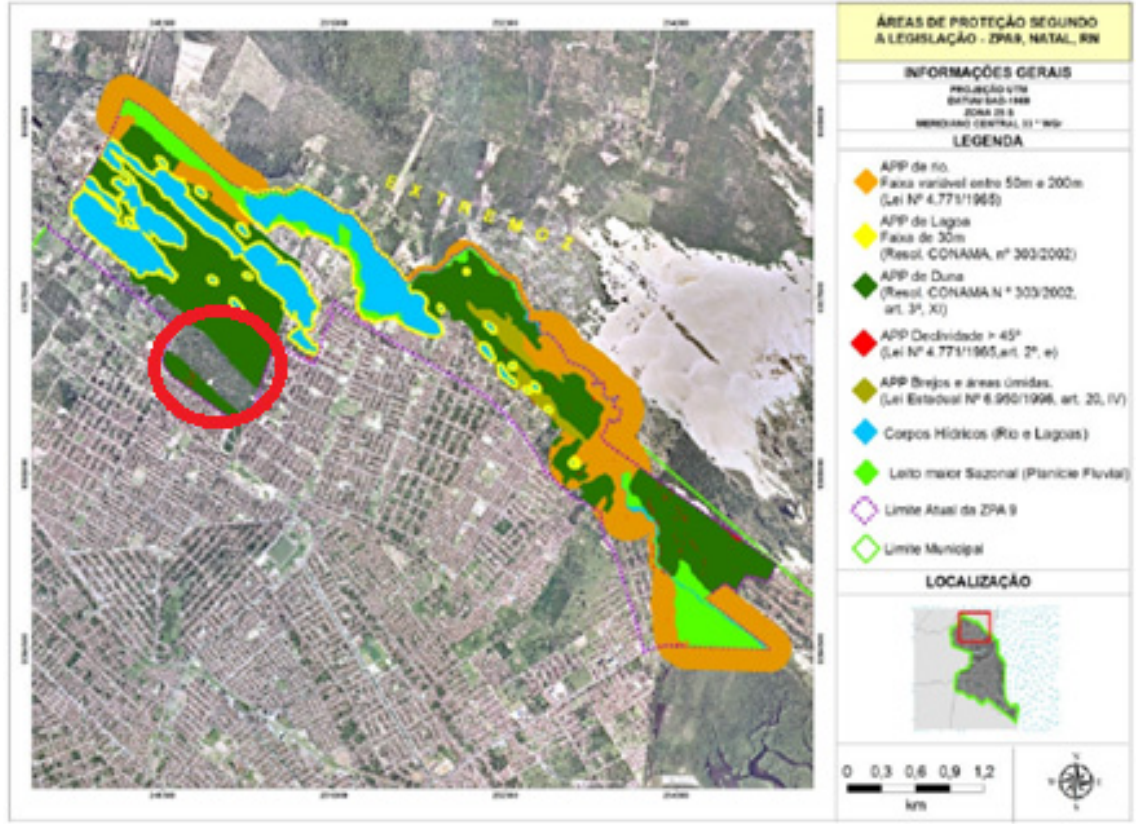

Figure 2: Location of the Moema Tinoco Project.

The urban fabric of Natal is marked by large spatial disparities. The city has a huge housing deficit in areas where there are jobs (and vice versa), needs quality public spaces, its sidewalks are inadequate, and the ugliness dominates the cityscape. As a result of this (un)territorial organization, the sub city takes advantage of its potential to generate social and economic value, and aggravates their mobility problems and social and territorial injustice. The urban chaos deepens with the growing supply of social housing in outlying areas of the city, and the consolidation of ghettos - gated communities of poor or rich. Natal faces crime problems, low social cohesion and economic inefficiency - an environment that does not boost innovation, creativity, entrepreneurship, or attracting global talent.

In northern Natal, $40 \%$ of the North Zone Natal population population live in neighborhoods where the ZPA-9 is inserted and in the neighborhoods of Lagoa Azul and Pajuçara average of residents per household is higher than the average for the capital and other districts in Natal/Brazil [4]. With regard to education: $80 \%$ of the population is literate, but most householders have a maximum of up to 7 years of study. (IBGE, 2000). Income: $60 \%$ of the residents of Lagoa Azul neighborhoods and Pajuçara earn up to three minimum salaries. In Lagoa Azul $26.57 \%$ earns up to 1 minimum wage. The average monthly income is lower than 
the city of Natal/RN and the North Zone [1]. Sanitation: North Zone has only $4.10 \%$ of sewage connection, practically does not exist in the neighborhoods mentioned herein. 20\% of Lagoa Azul streets and 30\% Pajuçara have drainage system [4].

Finally, specifically the North of Natal area where the project will be located, in Chapter 4 we will understand the details of the project and because sustainable as a case study.

\section{The Moema Tinoco Project in the 'My House, My Life' sustainable Brazilian program}

Public policies in the area of social housing focus in its guidelines, as a priority, combating quantitative housing deficit, a situation that affects $90 \%$ of families with monthly income between $0-3$ minimum wages.

Linked to this factor, the government initiatives aimed at reducing the deficit that stimulate come, in addition to the production of social housing, the mobilization of public investments for the development of the construction sector, generating jobs and income. The housing package launched by the Brazilian Federal Government, "My House, My Life" has the objective of reducing the housing deficit. The land regularization, rules of urban land use in urban centers, infrastructure and transformation policies of slums in neighborhoods are essential measures in this process.

It is also observed that aspects of economic, environmental and social order are treated sometimes in social housing projects in a timely manner, disregarding the integration of the guiding elements of sustainability. The above scenario requires deepening the discussion on the impact of real estate projects of social interest in the living conditions of the population and in the conception of urban planning of cities.

In this context, it highlights the importance of the proposed topic of significant relevance to society and the challenge of contributing to the implementation of sustainable social housing in Brazil.

The construction of large housing estates didn't prove to be a good solution and has generated other impacts: the absence of nearby jobs, away from institutions, trade and services, high infrastructure costs, real estate speculation in the areas between sets and urban sprawl, spatial segregation urban and other social costs.

On the other hand, the Moema Tinoco Project covers an area of $1,244,078.92 \mathrm{~m}^{2}$, and part of the area will be donated to the city of Natal for building purposes for a Natural Park and the rest will be built sustainable social housing. The project initiative provides an average of 20,000 inhabitants, considering that the project contained 4,000 housing and the assumption that each house will be 4 or 5 people, as figure 3 .

The greatest challenge of this project were attempts to regulate the area and consider it as an area of social interest, but still remains this debate. Another challenge is related to the project that the search for a logical and rational solution able to show that the characteristic of a housing not satisfy the economic pattern of an appointed social class, but the technical notions, breaking an ancient and 


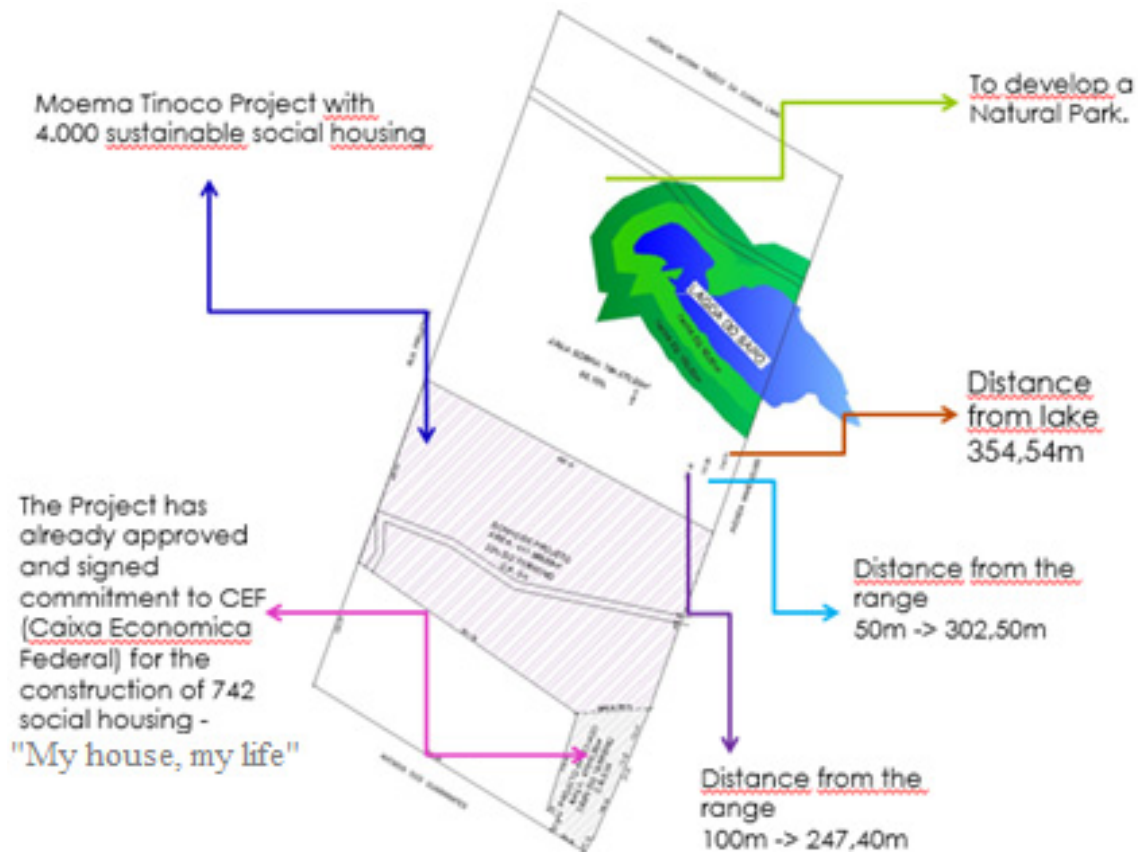

Figure 3: Details of the Moema Tinoco Project.

dominant paradigm that affordable housing should be marked by the simplicity of its buildings. The city of Natal need to awake a greater sense of urbanity.

As for legal aspects, Law no. 10.257/2001 instituted the City Statute, regulating articles 182 and 183 of the Brazilian Federal Constitution, was the essential guiding framework of the current urban policy. The Brazilian government has been creating other inventive policies, such as in March 2009 created the "My House, My Life".

The "Blue House Seal" of Caixa Econômica Federal (CEF) is also another element that aims to encourage the construction of sustainable housing developments. At the municipal level is the Director Plan of Natal which regulates benefits for housing.

The innovative elements are based on the search for balance of environmental protection, social justice and economic viability. This means that the sustainable housing project is an innovative way many Brazil's problems, especially Natal: the huge deficit of housing, the marginalization of low-income families, lack of social integration and a growing concern for the environment. Innovative also covered by the construction of 4,000 sustainable housing, say, on a large scale. This is important for the region of Natal, in front of mentioned problems.

Among the elements of architecture and urban project includes bike rack, place for selective collection and storage of recyclable materials, leisure areas and green areas, water-saving systems and energy processes to reduce and control the quality of construction materials and in the concept of the project, measures were taken to 
improve the thermal performance of the building, the surrounding community participation, tangible changes in access to opportunities, given that the project has an impact and potential large scale in the poorest region of Natal.

The Caixa Econômica Federal through "Blue House Seal", the company recognizes the rational use of water and natural resources, reduces maintenance costs of the buildings and the monthly expenses of its members, and also promotes awareness of entrepreneurs and residents about the benefits of sustainable buildings. Aiming to all these benefits, the Federal Savings Bank provides lowinterest rates for builders. So, it is this sustainable funding model that meets 0 income classes to 3 minimum wages within an available and affordable budget. The following figures in generally shows the project, see:

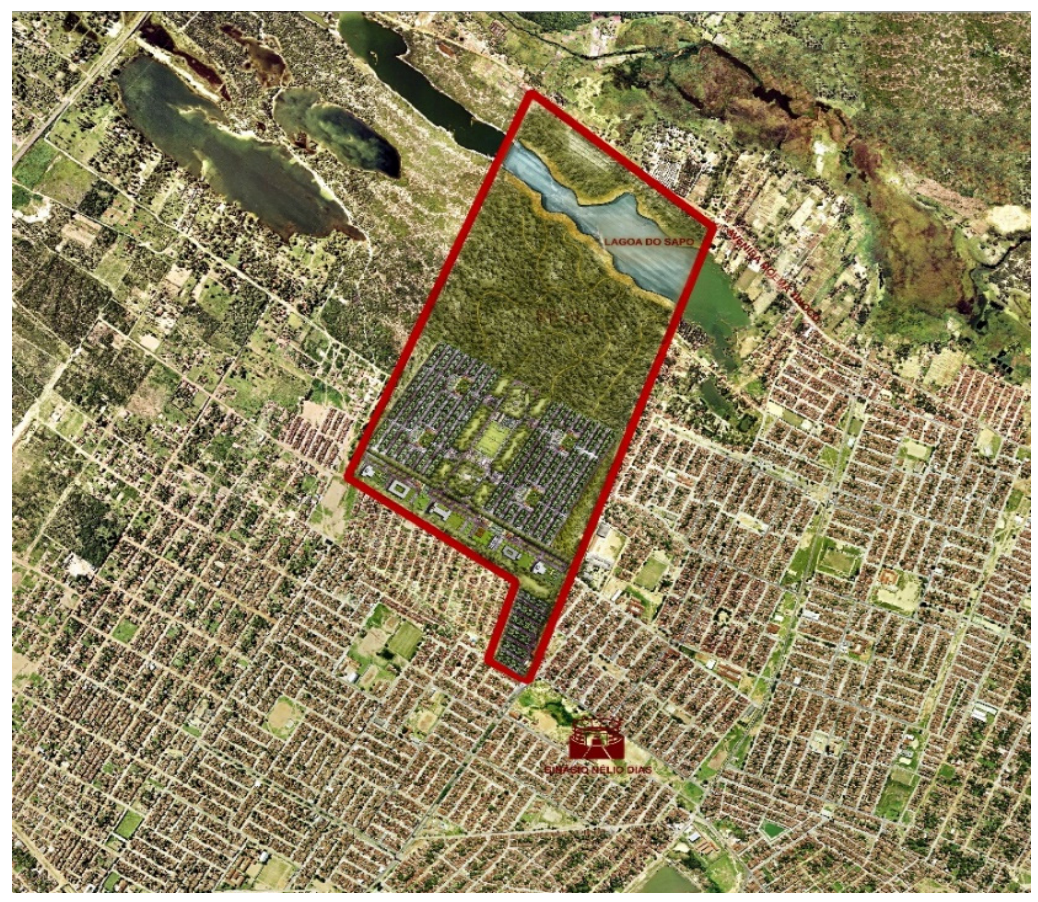

Figure 4: Distant view of Moema Tinoco Project.

The outlined architectural project shows us the possibility of building social housing (0-3 minimum wages), seeking an integration with the surrounding population, respecting sustainable ideas. The project was explained in Public Hearing for the purpose of the regulations of the Environmental Protection Zone-9 in Natal-RN, still pending. In addition, there was a meeting with the regional manager of Construction Federal Savings Bank (CEF) in RN, Ivonaldo Henrique de Souza, at which time this has shown considerable interest in the proposal. Marcelo Rosado, Municipal Secretary of Environment and Urbanism, in turn, did not think differently and considered that it is necessary to raise awareness of the importance of sustainability, as shown below: 


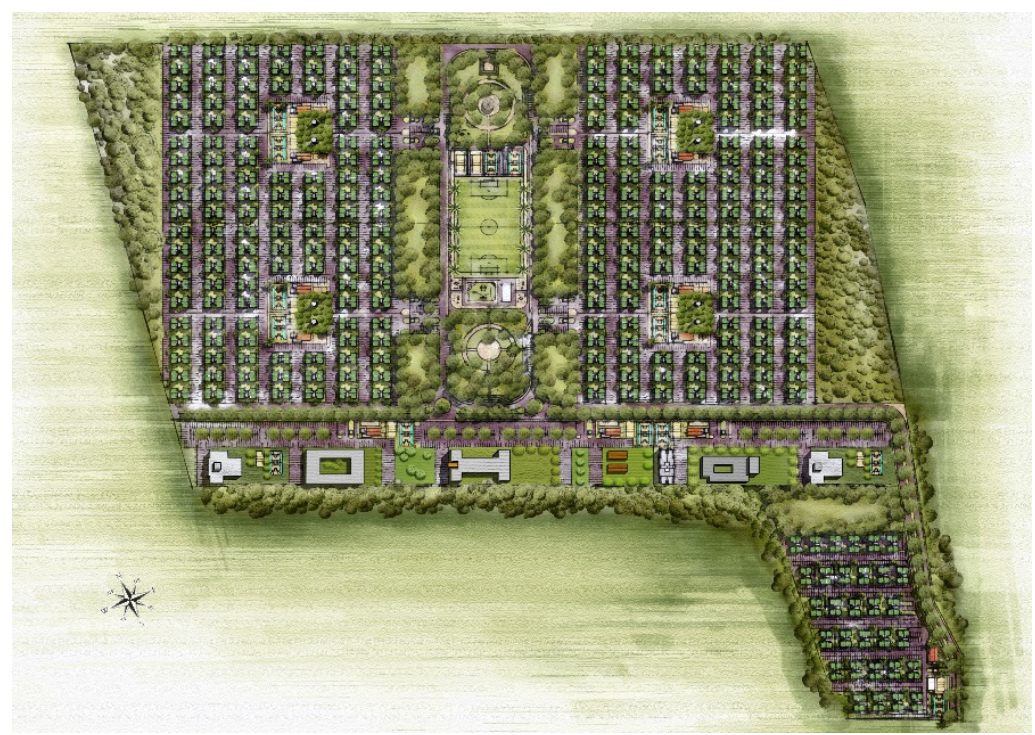

Figure 5: Moema Tinoco Project with approximate view.

Partly as a result there was also a meeting with Homero Grec, Secretary of Housing, Projects and Land Regularization Structuring - SEHARP - Natal, when it made alarming data weightings about the housing deficit in Natal and claimed that in the north there is no empty urban sufficient capacity for social housing in the range 1 as the area in question, although there resources of CEF for this purpose. Thus, the preliminary design studies developed complies with the requirements of the Blue House Seal of CEF in the silver level, but it is believed in the possibility of adding other optional criteria.

\section{Conclusions}

Sustainable housing production is a complex challenge for contemporary societies. It is not just to consider the preservation of environmental resources and the environment but, mainly, to ensure decent living conditions for users of these dwellings.

The axes of sustainable development in the contemporary city are based on the following pillars: economic, social, political, environmental and cultural, which must appear from the initial preparation of any project, that is, from the urban interventions, including the scenic route, to the details of the architectural design and monitoring the implementation of the building.

Thus, the citizen is the most important actor in the process to ensure the multiple dimensions of sustainability and the city of Natal, during all meetings with social and political actors, they have demonstrated the importance of the project and desire to contribute in some way, although didn't happen the regulation of Environmental Protection Zone in North of Natal, where the project is located 
to run, hinders progress. It was found that any viable and sustainable urban development plan requires the convergence of three powers - the social power, economic and political. Better city, more connected, more public spaces, mixed use and mixed income neighborhoods with easy access to public transportation, and less dependent on the car can only be achieved with the convergence of government forces, market and civil society.

\section{References}

[1] IBGE. Instituto Brasileiro De Geografia, E Estatística. (2010). Sinopse dos Resultados do Censo 2010. Available: http://www.censo2010.ibge.gov.br/ sinopse. April, 22 set. 2015.

[2] Rio Grande Do Norte. Ministério Público. Implicações ambientais e urbanísticas decorrentes da proposta de regulamentação da Zona de Proteção Ambiental 9 (ZPA 9), Município de Natal, RN. Laudo Pericial. Natal: MPRN/UFRN, 2012. Disponível em: http://www.natal.rn.gov.br/ semurb/paginas/File/modernatal/zpa09/ZPA9-LaudoPericialMP.p

[3] Instituto Brasileiro De Administração Municipal Modernatal: Projeto de modernização e gestão administrativa e fiscal do Município de Natal. Relatório Fase II. Módulo 3 - Urbanístico. Produto 4. Subprojeto 2: atualização e consolidação da legislação. PL8: Versão final da Zona de Proteção Ambiental 9 - ZPA 9. Natal: IBAM, 2010.

[4] Azevedo, P. G. Vulnerabilidades socioambientais na zona de proteção ambiental-9, Natal/RN/2010. 